\title{
The Italian Society of Pharmacology
} (SIF)

\author{
A. Mugelli \\ E-mail: alessandro.mugelli@unifi.it
}

The Italian Society of Pharmacology (SIF) is one of the oldest pharmacological societies in the world, being founded only after the American, British and German Societies.

SIF will celebrate its 80th anniversary on December 22nd, 2019: that same day, in 1939, the Society was officially established by the royal decree no. 2162 (at that time Italy was a kingdom).

However, the activity of SIF dates back to 1932 as attested by publications in the Archivio Italiano di Farmacologia, a scientific journal in Italian founded by Adriano Valenti who became President of the Society in 1940.

It was in 1969 that the Society decided to cease the publication of the Archivio Italiano di Farmacologia and approved a new journal in English as its official publication: Pharmacological Research

Communications, published by Academic Press. Alberto Giotti, Secretary of the Editorial Board, wrote in the Preface: [by approving the new Journal], "the Society will make a contribution to the science of pharmacology in bringing together the results of the work of individual researchers". Interestingly enough the first paper was a communication by HO Schild entitled "Parallelism of $\log$ dose-response curves in competitive antagonism". In 1989 the journal title has changed to "Pharmacological Research", the executive editor being Rodolfo Paoletti, and in 2012 it became an Elsevier journal. Short after, due to administrative issues, it ceased to be considered the official journal of SIF, despite the enduring commitment of the Society's members as Editors in Chief and their contribution to its editorial success in the Editorial board. Today the Italian Society of Pharmacology believes that it can make, as it did 50 years ago, a further contribution to the science of pharmacology by publishing a new journal named PharmaAdvances.

As Luca Pani has stated in the editorial, introducing number zero, PharmaAdvances is deeply rooted in the tradition of the Italian Society of Pharmacology, as I briefly recalled, but has the visionary intent to embrace the whole lifespan of a drug, from its discovery and development to its clinical pre-and post-marketing evaluation, including the associated ethical aspects. In a way PharmaAdvances will provide an open forum for presenting high-quality experimental results and for discussing issues associated with drug development and the use of therapeutics within the context of access and sustainability.

For those who do not believe in coincidences, Alberto Giotti was my unforgettable mentor.

(C) 2019 The Italian Society of Pharmacology (SIF) Published by EDRA SPA. All rights reserved 